\title{
Chestnut Leaf Inoculation Assay as a Rapid Predictor of Blight Susceptibility
}

\begin{abstract}
Andrew E. Newhouse, State University of New York College of Environmental Science and Forestry, Department of Environmental and Forest Biology, Syracuse, NY; Jesse E. Spitzer, North Carolina State University, Cooperative Tree Improvement Program, Department of Forestry and Environmental Resources, Raleigh, NC; Charles A. Maynard, State University of New York College of Environmental Science \& Forestry, Department of Forest and Natural Resources Management, Syracuse, NY; and William A. Powell, State University of New York College of Environmental Science and Forestry, Department of Environmental and Forest Biology, Syracuse, NY
\end{abstract}

\begin{abstract}
Newhouse, A. E., Spitzer, J. E., Maynard, C. A., and Powell, W. A. 2014. Chestnut leaf inoculation assay as a rapid predictor of blight susceptibility. Plant Dis. 98:4-9.

American chestnuts (Castanea dentata), effectively eliminated from eastern North America by chestnut blight in the twentieth century, are the subject of multiple restoration efforts. Screening individual trees (or tree types) for blight resistance is a critical step in all of these programs. Traditional screening involves inoculating stems of $>3$-year-old trees with the blight fungus (Cryphonectria parasitica), then measuring resulting cankers a few months later. A quicker, nondestructive, quantitative assay, usable on younger plants, would enhance restoration efforts by speeding the screening process. The assay presented here meets these requirements by inoculating excised leaves with the blight

lected from few-month-old seedlings or fully mature trees, and results are measured after less than a week. Leaves from several lines of both American and Chinese chestnuts were inoculated, as well as the congener Allegheny chinquapin, and experimental leaf assay results correlate well with stem assay results from these species. Inoculations with virulent and hypovirulent blight fungi strains also showed relative patterns similar to traditional inoculations. Given the correlations to established stem assay results, this procedure could be a valuable tool to quickly evaluate blight resistance in American chestnut trees used for restoration.
\end{abstract} fungus and measuring resulting necrotic lesions. Leaves can be col-
The American chestnut (Castanea dentata (Marshall) Borkh.) was once a widespread and integral part of the ecology and economy of the eastern United States. The timber was strong, straightgrained, and rot-resistant, and the nuts provided nutrition and income to humans, as well as a reliable mast crop for wildlife. However, starting around the turn of the twentieth century, chestnut blight eradicated nearly all mature American chestnut trees throughout the chestnut's North American range. Chestnut blight is caused by the necrotrophic fungal pathogen Cryphonectria parasitica (Murr.) Barr., which colonizes bark wounds, causes cankers, and eventually girdles trunks of susceptible trees. No practical prevention or treatment methods have been found for landscapescale use, and various restoration programs have been underway for many years with the goal of producing blight-resistant trees. Success in these programs is determined by field inoculation trials, which typically involve inoculating trees that have been growing outdoors for at least 3 years $(9,12)$. While American chestnut grows relatively quickly compared to other North American hardwoods, it still may be 5 years or more before a given tree can be screened for blight resistance.

Any American chestnut restoration project would be expedited by an earlier screening assay, which could eliminate the most susceptible trees before they are planted outside, and focus limited resources on trees that show the most promise for blight resistance. An ideal early screening assay would be simple, repeatable, nondestructive to the tree, and quantitative, or able to detect intermediate levels of resistance. This assay should also correlate with results

Corresponding author: William A. Powell, E-mail: wapowell@esf.edu

Accepted for publication 7 June 2013.

http://dx.doi.org/10.1094/PDIS-01-13-0047-RE

(C) 2014 The American Phytopathological Society from established field inoculation protocols. Specifically, it is well known that pure American chestnuts are much more susceptible to chestnut blight than Chinese chestnuts (C. mollissima), so a new assay should readily confirm this difference. Also, if the assay can resolve differences between species such as Allegheny chinquapin that have known intermediate levels of resistance between American and Chinese chestnuts (8), it will be more useful in analyzing potential American chestnut restoration material. A "small stem assay" method (24) has been published that meets some of these criteria, but this relies on $\sim 1$-year-old trees, and even trees with moderate levels of blight resistance are notably damaged (or must be cut back) after the screening.

Given the inherent limitations to chestnut stem inoculations, an excised-leaf inoculation is a promising alternative. Even though $C$. parasitica doesn't normally infect the leaves of chestnut, the procedure presented here meets all the criteria of the ideal assay described above: It can be used on trees that are only a few months old without causing significant damage, setup and measurements are straightforward and not weather-dependent, results are obtained in only a few days, and data match well with those from traditional stem assays.

\section{Materials and Methods}

Inoculations were done primarily with 2 strains of $C$. parasitica that are used by The American Chestnut Foundation's blight screening program: SG2-3, a moderately virulent strain (12), and EP155, a highly virulent strain (ATCC38755). Both strains have been extensively studied, including genome sequencing, and were provided by Donald Nuss, University of Maryland, IBBR. A hypovirulent strain, isogenic to EP155, was also tested. This strain, EP713, was created from EP155 infected with hypovirus CHV1713 (Courtesy of Sandra Anagnostakis, Connecticut Agricultural Experiment Station). These cultures were maintained on potato dextrose agar (PDA, Difco) and subcultured 3 to 5 days before the assay was started. Plugs of agar with $C$. parasitica were created 
with a \#1 cork borer ( $\sim 3 \mathrm{~mm}$ diameter) around the actively growing border of the colony (Fig. 1A) less than $2 \mathrm{~h}$ before each inoculation experiment was started.

American chestnut (AC), Chinese chestnut (CC), and Allegheny chinquapin (Castanea alleghenensis) leaves were collected from actively growing plants in a growth chamber or greenhouse. See Table 1 for leaf varieties used and background or source information. According to pilot studies, ideal leaves were fully expanded and no longer red, but still soft and pliable. Leaves of different types were chosen to be as similar as possible in terms of size and age. If leaves were collected outdoors, they were soaked in $0.01 \%$ Tween 20 for approximately $5 \mathrm{~min}$ with occasional gentle agitation, rinsed twice by soaking in distilled water, and gently blotted dry. (Outdoor leaves tend to develop secondary infections if they are not washed; leaves from a clean greenhouse or growth chamber did not require this wash.) Each leaf was labeled and numbered. Inoculations were started less than $2 \mathrm{~h}$ after leaf collection.

Midvein tissue on the abaxial (bottom) leaf surface was selected as an inoculation location to simulate the vascular stem tissue where chestnut blight naturally occurs. Midvein sections $5 \mathrm{~mm}$ long were delineated with a marker on each leaf. The first of these inoculation sites was always located within 2 to $4 \mathrm{~cm}$ of the petiole, and if the leaf was large enough ( $>15 \mathrm{~cm}$ overall length), a second inoculation site was located approximately in the middle of the leaf. Each inoculation site was wounded by slicing with a \#11 scalpel along the length of the midvein to approximately half the depth of the midvein (Fig. 1B). This slice wound should be deeper than a surface scratch, but should not penetrate all the way through the leaf. Immediately after wounding, one inoculated agar plug was placed mycelia-side-down directly on each wound (Fig. 1C). The plug was pressed firmly down against the midvein to ensure good contact between the fungus and the wound, but not pressed hard enough to break or dislodge the plug. Control PDA plugs without fungi were also included on separate leaves.

The leaf with agar plugs was then placed in a plastic tray with a gasket-sealed locking lid (Sterilite Ultraseal 16-cup Rectangle or equivalent) lined with slightly damp paper towels (Fig. 1D; towels should be evenly damp but not saturated or dripping.) Each tray could hold 6 to 12 inoculated leaves, and leaf types were spread evenly among all trays in an experiment to eliminate any individual tray effects. Trays were incubated in the dark (either wrapped in foil or placed in a closed cabinet) at room temperature (21 to $25^{\circ} \mathrm{C}$ ). After 4 to 7 days, necrosis surrounding each inoculation was measured in terms of length of the discolored lesion immediately along the midvein, on the axial (top) leaf surface (Fig. 1E) To confirm that $C$. parasitica was responsible for the necrosis, in two separate experiments a section of necrotic leaf outside the initial inoculation area was removed, cultured on $2 \%$ agar (water agar), and subcultured to PDA.

Approximately 8 to 10 leaves of each type (mean $=10$ inoculations per leaf type per experiment, range 6 to 20) were used in each experiment (an "experiment" is considered a series of leaves inoculated with a single strain of $C$. parasitica at a single time point). In each experiment, a leaf type consisted of leaves from a single source (Table 1). A total of 17 comparison experiments were completed: 5 with EP155 (1 of which also tested EP713), and 12 with SG2-3 (2 of which included chinquapins as well as American and Chinese chestnuts). All experiments except for the 2 chinquapin comparisons used simple length measurements, in which necrosis
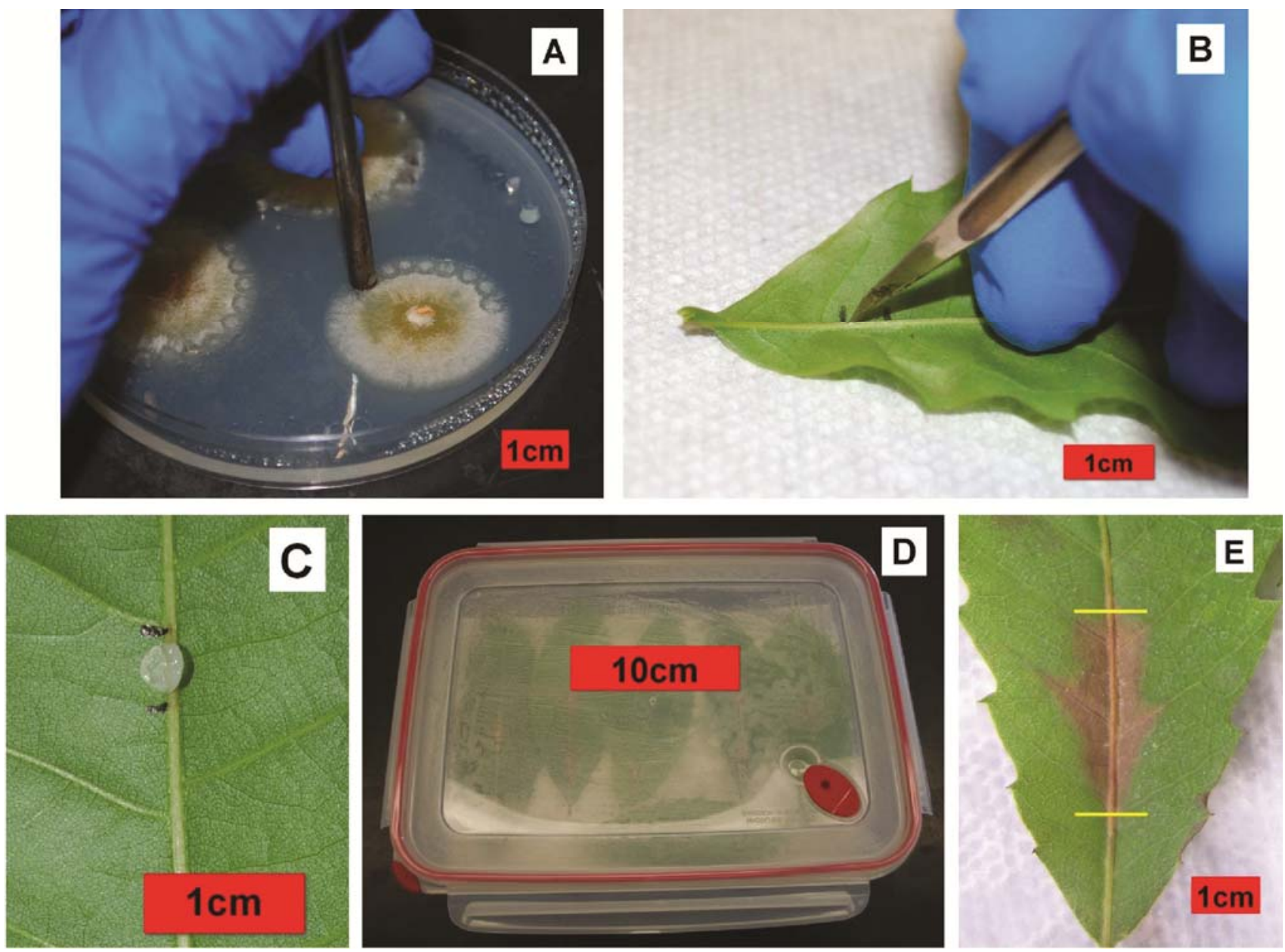

Fig. 1. Illustrated leaf assay protocol. A, Use a cork borer to create plugs of Cryphonectria parasitica from the border of a colony growing on potato dextrose agar. B, Wound the leaf midvein with a light scalpel slice. C, Place plug on a leaf, ensuring the fungus firmly contacts the wound on the midvein. D, Incubate leaves in a dark gasket-sealed tray for about 5 days. $\mathrm{E}$, Measure necrosis in terms of length along midvein, on top leaf surface: yellow bars indicate measurement boundaries. 
was measured in terms of length along the midvein. The chinquapin comparisons used approximate necrotic area measurements for all leaf types, assuming an approximately diamond-shaped necrotic area (length*width/2). Measurements from each leaf type in each experiment were averaged, and $\mathrm{AC}$ versus $\mathrm{CC}$ averages were compared using one-tailed $t$ tests (SAS for Windows 9.2). Leaf types with intermediate levels of resistance were compared to AC and $\mathrm{CC}$ controls with more conservative two-tailed $t$ tests.

During the development of this assay, several variables were tested to find out which conditions were most conducive to differentiating leaves with known susceptibility differences; these are detailed in Table 2. Only the final or "successful" conditions and techniques have been described in the text above. Modifications on the current techniques were tested, including pinning an agar plug to the leaf (which could create a wound while holding the inoculum to the leaf), using a liquid inoculum suspension instead of a plug, inserting the petiole end of a leaf directly into an agar plug, and various leaf washing methods. Experimental variables tested included moisture quantity in the tray, tray type, methods of covering or sealing the tray, incubating in presence of light, length of incubation time, leaf age, and leaf source (outdoor versus indoor/greenhouse).

\section{Results}

A total of 335 individual inoculations were performed across 17 experiments under the reported conditions, and greater than $98 \%$ of those $(n=329)$ showed at least some necrosis. Control inoculations (agar plugs without fungi) showed minor discoloration on the wound itself, but no lesions formed apart from the original wound. Inoculations that resulted in no necrosis, i.e., those that "didn't take," were not included in analyses because infection was not initiated.
Mean necrotic lengths (or areas, for chinquapin comparisons) were compared between each leaf type after each experiment. In every experiment, the mean necrotic length on $\mathrm{AC}$ leaves was greater than that on $\mathrm{CC}$ leaves. All five experiments with strain

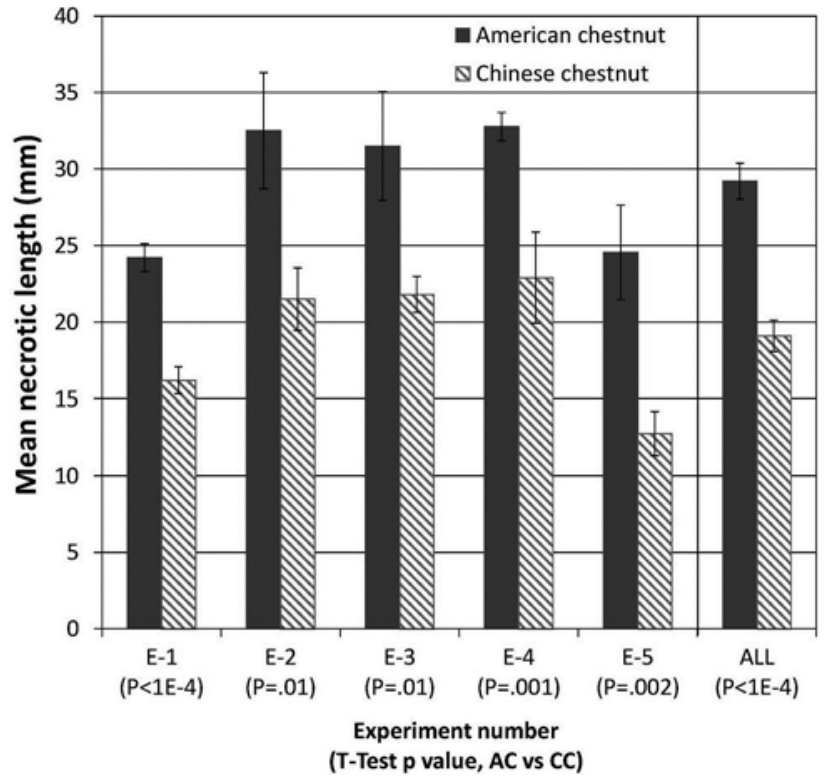

Fig. 2. Cryphonectria parasitica strain EP155 leaf inoculations, American chestnut and Chinese chestnut. Error bars indicate $+/-1$ standard error of the mean. All five individual experiments show a significant difference between American and Chinese chestnut lesion sizes. (Maximum $P=0.01$ )

Table 1. Sources of chestnut seedlings

\begin{tabular}{|c|c|c|c|}
\hline Castanea species & Line name & $\begin{array}{l}\text { Inoculum used } \\
\text { (number of inoculations) }\end{array}$ & Source \\
\hline C. alleghenensis & Allegheny Chinquapin & SG2 (23) & Empire Chestnut Company, Carrolltown, OH, Greg Miller \\
\hline C. dentata & Degolyer & SG2 (10) & Zoar Valley Orchard, NY, TACF-NYa, Herb Darling \\
\hline C. dentata & Ellis 1 & SG2 (12) & John Ellis, via TACF-NY \\
\hline C. dentata & I64-J2 & EP155 (10) & Zoar Valley Orchard, NY, TACF-NY, Herb Darling \\
\hline C. dentata & Kemp & SG2 (26) & Zoar Valley Orchard, NY, TACF-NY, Herb Darling \\
\hline C. dentata & Lasdon & EP155 (21) & Lasdon Park Arboretum, NY, TACF-NY, Craig Hibben \\
\hline C. dentata & WB275-27 & SG2 (21), EP155 (8) & H. Dayton Wilde, via Fred Hebard, Meadowview Farm, VA, TACF \\
\hline C. dentata & Zoar & SG2 (39), EP155 (10) & Zoar Valley Orchard, NY, TACF-NY, Herb Darling \\
\hline C. mollissima & Cropper & SG2 (30), EP155 (9) & Auburn University Agricultural Experiment Station (10) \\
\hline C. mollissima & Hong Kong & SG2 (21) & $\begin{array}{l}\text { M. Nave, Sacramento, CA, via Empire Chestnut Company, } \\
\text { Carrolltown, OH, Greg Miller }\end{array}$ \\
\hline C. mollissima & Qing & SG2 (55), EP155 (34) & Empire Chestnut Company, Carrolltown, OH, Greg Miller \\
\hline
\end{tabular}

a TACF-NY $=$ The American Chestnut Foundation, New York Chapter.

Table 2. Experimental variations tested

\begin{tabular}{|c|c|}
\hline Condition or variation & Result compared to reported conditions: solution or alternative if applicable \\
\hline Agar plug pinned to leaf & Plug split in half, and/or no infection initiated \\
\hline Liquid inoculum applied to wound & Liquid rolled away from wound, infected leaf tissue apart from wound \\
\hline Petiole inserted into larger plug & Infection spread very slowly ( $>4$ weeks instead of $<1$ week) \\
\hline Increased moisture in tray (leaves on water-saturated surface) & Increased secondary fungal infections \\
\hline Decreased moisture in tray & Agar plugs desiccated, leaves dried, fungus didn't spread \\
\hline Unsealed cover, or plastic wrap over glass tray & Tray dried too quickly, see "Decreased moisture" above \\
\hline Incubation under growth lights $\left(\sim 100-150 \mu \mathrm{M} / \mathrm{m}^{2} / \mathrm{s}\right)$ & Agar plugs desiccated, more inoculations failed to initiate infections \\
\hline Increased incubation time & $\begin{array}{l}\text { Multiple inoculations on single leaves converged, fungus overgrew leaf, increased } \\
\text { secondary infections }\end{array}$ \\
\hline Decreased incubation time & $\begin{array}{l}\text { Discriminatory power decreased, but 3-day incubations can be beneficial for } \\
\text { smaller/younger leaves (26) }\end{array}$ \\
\hline Young (softer) leaves & Infections spread more quickly: avoid, or measure earlier \\
\hline Old (tougher, thicker) leaves & $\begin{array}{l}\text { Intentional infections spread slower, less discriminatory power between types, more } \\
\text { secondary infections can develop }\end{array}$ \\
\hline Outdoor (dirtier) leaves, no rinse & Secondary infections developed: wash in mild detergent, see text \\
\hline Outdoor leaves, rinsed with $\mathrm{dH}_{2} \mathrm{O}$ & Insufficient wash, secondary infections developed \\
\hline Outdoor leaves, soaked in $10 \%$ bleach, then rinsed in $\mathrm{dH}_{2} \mathrm{O}$ & $\begin{array}{l}\text { Apparently too harsh, secondary infections developed at rates greater than in unwashed } \\
\text { leaves }\end{array}$ \\
\hline
\end{tabular}


EP155 showed a statistically significant difference between necrosis on $\mathrm{AC}$ and $\mathrm{CC}$ leaves (Fig. 2, $P<0.01$ in each experiment). The overall AC mean necrotic length across all EP155 experiments was $29.2 \mathrm{~mm}$, while the overall $\mathrm{CC}$ mean was $19.1 \mathrm{~mm}$. All but one of the SG2-3 experiments (11 out of 12) also showed a significant difference between $\mathrm{AC}$ and $\mathrm{CC}$ necrosis (Fig. 3, starred $P$ is the only value above 0.05 ). The overall AC mean necrotic length across all SG2-3 experiments was $28.5 \mathrm{~mm}$, while the overall CC mean was $20.2 \mathrm{~mm}$. Each experiment was analyzed separately since they were done at separate times, so environmental conditions and timing between different experiments may vary slightly. Interestingly, the less virulent strain (SG2-3) produced average necrotic lengths that were not significantly different overall than the more virulent strain (EP155), but since they were not done at the same time under exactly the same conditions, inter-experimental comparisons like these are not necessarily meaningful.

One experiment directly compared necrosis between fungal strains of known relative virulence (virulent EP155 versus isogenic hypovirulent EP713). Both AC and CC leaves showed significantly different levels of necrosis between the virulent and hypovirulent strains $(P<0.001$, Fig. 4). In both experiments which compared Allegheny chinquapins to Chinese and American chestnuts, the chinquapins showed an intermediate level of resistance, which was significantly different than both congeners $(P<0.022$, Fig. 5).

When necrotic leaf tissue was excised after an inoculation and cultured on water agar, mycelia grew and were subcultured to PDA. The resulting colony on PDA was identical to the initial $C$. parasitica colony in terms of general morphology, growth form, and color.

\section{Discussion}

The chestnut leaf assay described here is similar to assays used in a variety of other phytopathological systems. Some examples include screening for late blight in potatoes (6), rice blast (16) and sheath blight (18) in rice, Pythium root rot in chrysanthemums (23), Sclerotinia rot in oilseed rape (4), Botrytis and Sclerotinia infections in carrot (25), white mold in soybean (2), and head blight in wheat (1). Woody plant diseases for which leaf assays have been employed include citrus canker and citrus bacterial spot (7), Phytophthora ramorum on several Canadian forest tree species (15), black pod disease in cocoa (22), anthracnose (17) and downy mildew (3) in grape, various Phytophthora diseases on Strawberry trees (21), fire blight on apple trees $(5,20)$, leaf blight and anthracnose in poplar (14), and Septoria in poplar (19). A notable example from a closely related system was used to screen tanoak (also in the Fagaceae family) for sudden oak death susceptibility $(11,13)$. Finally, Zhang et al. (26) recently used a slightly modified version of this chestnut leaf assay to compare lines of transgenic American chestnut, some of which showed enhanced resistance to chestnut blight. Many of the diseases tested with these leaf assays involve

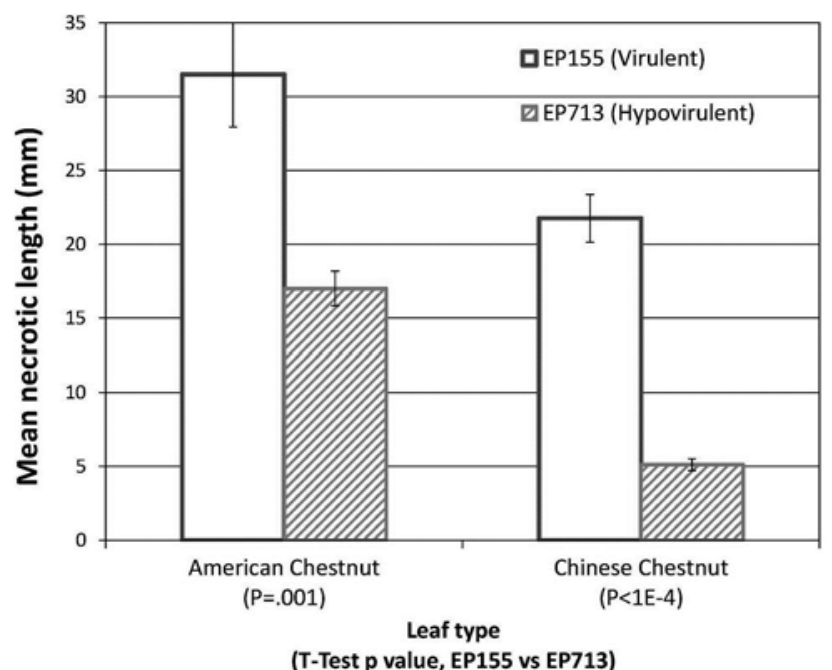

Fig. 4. Cryphonectria parasitica strain comparison leaf inoculation, EP155 (virulent) and EP713 (hypovirulent). Error bars indicate +-1 standard error of the mean. The virulent EP155 produces significantly more necrosis than the hypovirulent EP713 on both American $(P=0.001)$ and Chinese $(P<1 \mathrm{E}-4)$ chestnut leaves.

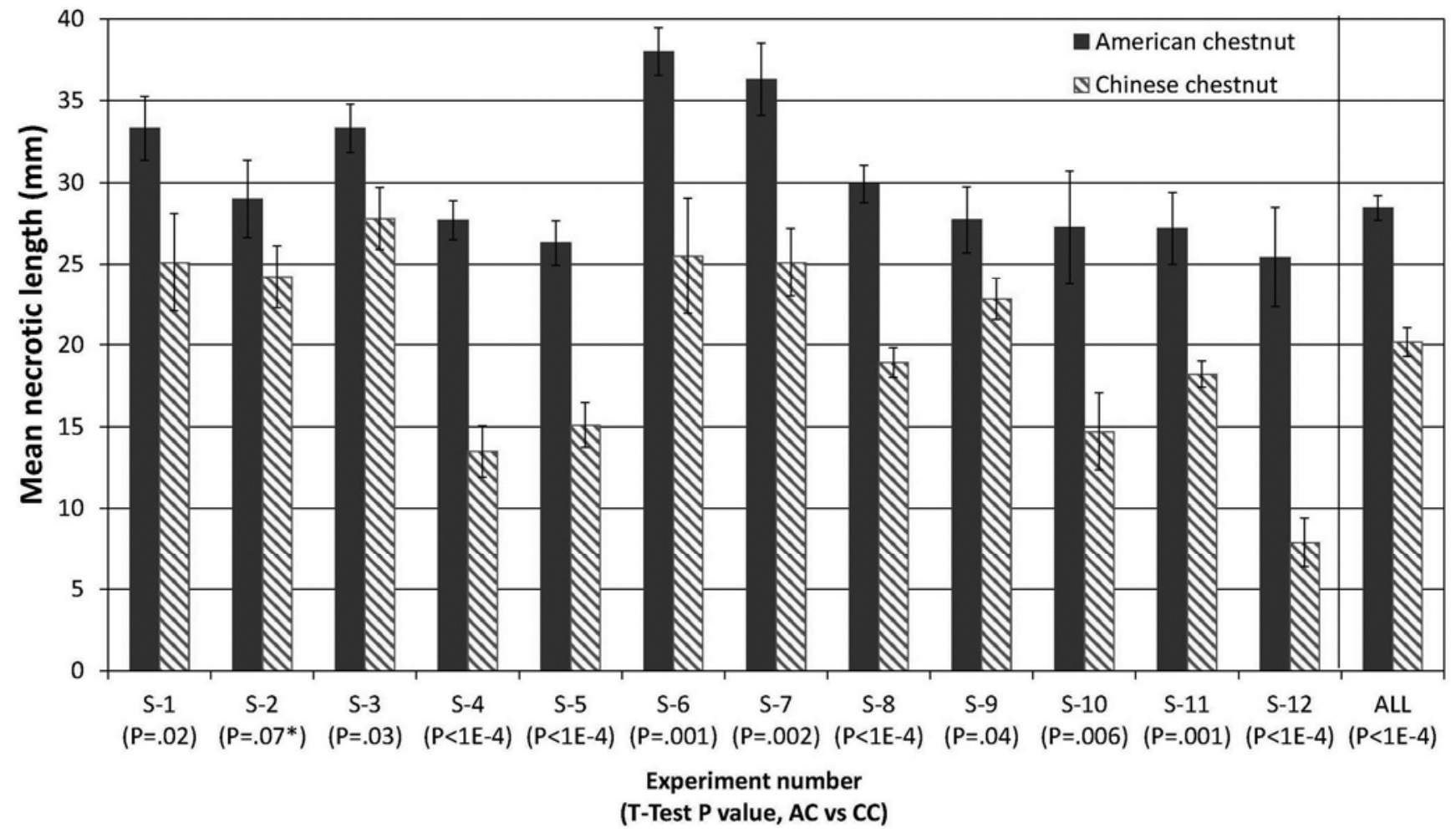

Fig. 3. Cryphonectria parasitica strain SG2-3 leaf inoculations, American chestnut and Chinese chestnut. Error bars indicate $+/-1$ standard error of the mean. All 12 individual experiments show the trend that American chestnut leaves have larger necrosis than Chinese chestnut leaves; 11 of 12 are statistically significant $(P<0.05)$. 
pathogens that naturally infect leaf tissue, either on the host or on other species. C. parasitica is not a leaf pathogen, but the leaf response may be useful for predicting the response in the stem, even if the mechanism is not identical. Other researchers have reached similar conclusions: Martinez-Bilbao et al. tested resistance to fire blight (Erwinia amylovora) in apple (20), and Moralejo et al. tested resistance to Strawberry tree blight caused by various Phytophthora species (21). Both compared leaf assays to shoot or twig assays, and results were at least similar enough to be useful for preliminary selection.

An assay of this type, which does not exactly simulate field disease conditions, is only useful if it correlates to established levels of host susceptibility under typically tested conditions. Indeed, several of the leaf assay references mentioned above concluded that leaf assays can be good general predictors of natural disease response, or useful preliminary selection tools, even if results don't exactly match those from whole-plant experiments $(3,7,17,20,22)$. That is the case with this chestnut leaf assay: even though $C$. parasitica is not a leaf pathogen, the leaf response to $C$. parasitica inoculation in these assays correlates to known host susceptibility. Specifically, American chestnut leaves consistently showed more necrosis than Chinese chestnut leaves in this assay. This pattern matches field inoculations and natural observations, in which American chestnut stems show larger cankers than Chinese chestnut stems (8). The single SG2-3 experiment that failed to detect a statistically significant difference between AC and CC leaves still showed the same trend, and recent measurement modifications that account for necrotic width appear to show better resolution, and emphasize differences between the species. Statistically significant trends were maintained in experiments with virulent versus hypovirulent strains of $C$. parasitica, and with leaves from multiple seed lots of both chestnut species. Additionally, Allegheny chinquapins showed leaf necrosis that was intermediate between $\mathrm{AC}$ and CC necrosis levels, and significantly different than both species, again matching field inoculations and historical observations (8). This demonstrates that the assay can apparently distinguish intermediate levels of host susceptibility, which is especially important for restoration programs.

Although this assay can clearly detect differences in the pathogen's virulence, as seen with the virulent and hypovirulent strains, it was not able to consistently distinguish differences between the moderately virulent SG2-3 and the highly virulent EP155 strains of C. parasitica. This might be due to the short duration of the assay

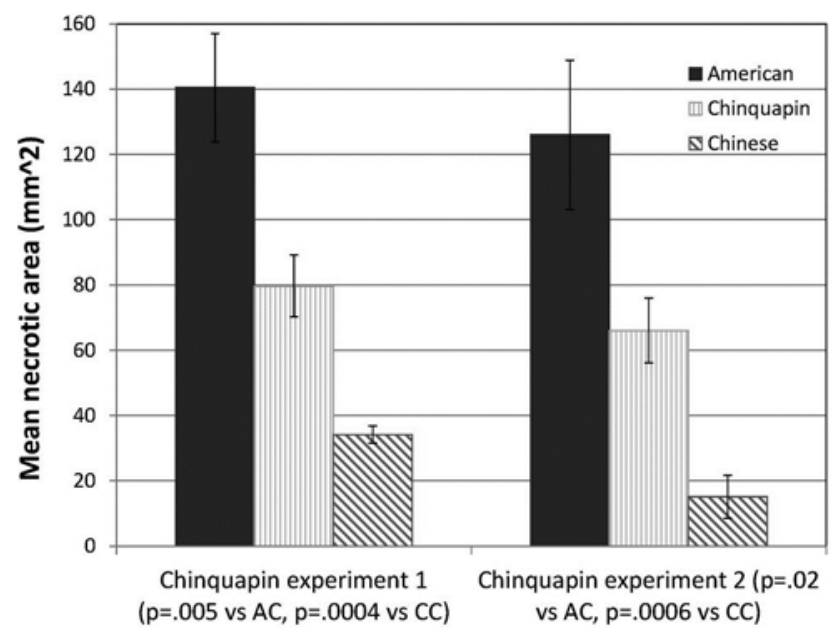

Fig. 5. Cryphonectria parasitica strain SG2 leaf inoculations comparing Allegheny chinquapins to American and Chinese chestnuts. Error bars indicate $+/-1$ standard error of the mean. In both experiments, chinquapins show necrosis that is intermediate between American and Chinese chestnuts, and significantly different than both $(P<0.022, n=9$ to 13 inoculations per leaf type per experiment). Data from American and Chinese leaves is repeated from Figure 3, Experiments S-11 and S12 , but in this chinquapin experiment, approximate necrotic area is used instead of only length. compared to stem assays. The longer duration of stem assays might allow for the smaller differences in virulence to be detected. Although stem assays might be able to detect finer differences in pathogen virulence and possibly host resistance, this leaf assay is primarily valuable in its consistent results differentiating the resistant Chinese from susceptible American chestnut trees, and distinguishing intermediate lines from both species. Further, preliminary observations indicate that more accurate measurements of leaf necrosis (i.e., using leaf scanning software to calculate necrotic area, rather than manually measuring length) will allow even finer resolution between leaf types and pathogen strains. Indeed, the most recent experiments completed (including the chinquapin comparisons) were measured in terms of approximate area, which provided more differentiation between species and better reflected qualitative visual differences in necrosis between leaf types. Length measurements alone were used for most experiments described in this article because they are simple, inexpensive, efficient, and easily repeatable.

While the "unsuccessful" parameters detailed in Table 2 were not used in the reported experiments, general results from alternative experimental variations are described to prevent repetition in the future. While optimal leaf properties and experimental conditions have been described, the most important consideration is that leaves of various types are as similar as possible.

Since it generally correlates well with established field screening methods, this assay has the potential to estimate chestnut blight host susceptibility much earlier and more rapidly than previously described tests, and to do so with much less damage to the host. This is particularly useful for unique, high-value trees that may be used in a restoration program, such as those from breeding programs or transgenic programs. Other studies that may not be directly related to restoration efforts (i.e., hypovirulence research, or other observations of $C$. parasitica activity) could also benefit from this assay. Additionally, it can potentially reduce the labor and acreage required for field inoculations, by identifying and eliminating the most susceptible lines or individuals before they are even planted. Thus, this assay meets the goals of a quick, simple, nondestructive screening method that can be used on younger chestnut trees to enhance chestnut breeding and restoration programs.

\section{Acknowledgments}

Funding was provided by the Forest Health Initiative and The American Chestnut Foundation. Thanks to Glen Stanosz (University of Wisconsin-Madison) and Katherine Hayden (University of California Berkeley) for consultation and help with assay development; to all providers of nuts and trees, especially Herb and Jane Darling, New York chapter of The American Chestnut Foundation; and to Aaron Barrigar, Clara Miller, Kathleen Baier, Megan Newhouse, Rachel Burris, and Sara Fitzsimmons for help with measurements.

\section{Literature Cited}

1. Browne, R. A., and Cooke, B. M. 2004. Development and evaluation of an in vitro detached leaf assay for pre-screening resistance to Fusarium head blight in wheat. Eur. J. Plant Pathol. 110:91-102.

2. Cunha, W. G., Tinoco, M. L. P., Pancoti, H. L., Ribeiro, R. E., and Aragão, F. J. L. 2010. High resistance to Sclerotinia sclerotiorum in transgenic soybean plants transformed to express an oxalate decarboxylase gene. Plant Pathol. 59:654-660.

3. Deglene-Benbrahim, L., Wiedemann-Merdinoglu, S., Merdinoglu, D., and Walter, B. 2010. Evaluation of downy mildew resistance in grapevine by leaf disc bioassay with in vitro- and greenhouse-grown plants. Am. J. Enol. Vitic. 61:521-528.

4. Dong, X., Ji, R., Guo, X., Foster, S. J., Chen, H., Dong, C., Liu, Y., Hu, Q. and Liu, S. 2008. Expressing a gene encoding wheat oxalate oxidase enhances resistance to Sclerotinia sclerotiorum in oilseed rape (Brassica napus). Planta 228:331-340.

5. Donovan, A. 1991. Screening for fire blight resistance in apple (Malus pumila) using excised leaf assays from in vitro and in vivo grown material. Ann. Appl. Biol. 119:59-68

6. Dorrance, A. E., and Inglis, D. A. 1997. Assessment of greenhouse and laboratory screening methods for evaluating potato foliage for resistance to late blight. Plant Dis. 81:1206-1213.

7. Francis, M. I., Pena, A., and Graham, J. H. 2010. Detached leaf inoculation of germplasm for rapid screening of resistance to citrus canker and citrus bacterial spot. Eur. J. Plant Pathol. 127:571-578.

8. Graves, A. H. 1950. Relative blight resistance in species and hybrids of 
Castanea. Phytopathology 40:1125-1131.

9. Griffin, G. J., Hebard, F. V., Wendt, R. W., and Elkins, J. R. 1983. Survival of American chestnut trees: Evaluation of blight resistance and virulence in Endothia parasitica. Phytopathology 73:1084-1092.

10. Harris, H., Norton, J. D., and Moore, J. C. 1980. Three New Chinese Chestnuts: AU-Cropper, AU-Leader, and AU-Homestead - their History and Production. Auburn Univ. Agric. Exp. Stn. Circ. 247.

11. Hayden, K. J., Nettel, A., Dodd, R. S., and Garbelotto, M. 2011. Will all the trees fall? Variable resistance to an introduced forest disease in a highly susceptible host. For. Ecol. Manage. 261:1781-1791.

12. Hebard, F. V. 2005. The backcross breeding program of the American Chestnut Foundation. J. Am. Chestnut Foundation 19:55-78

13. Huberli, D., Hayden, K. J., Calver, M., and Garbelotto, M. 2012. Intraspecific variation in host susceptibility and climatic factors mediate epidemics of sudden oak death in western US forests. Plant Pathol. 61:579-592.

14. Jia, Z., Gou, J., Sun, Y., Yuan, L., Tang, Q., Yang, X., Pei, Y., and Luo, K. 2010. Enhanced resistance to fungal pathogens in transgenic Populus tomentosa Carr. by overexpression of an nsLTP-like antimicrobial protein gene from motherwort (Leonurus japonicus). Tree Physiol. 30:1599-1605.

15. Jinek, A., Simard, M., Briere, S., Watson, A. K., Tweddell, R. J., and Rioux, D. 2011. Foliage susceptibility of six eastern Canadian forest tree species to Phytophthora ramorum. Can. J. Plant Pathol. 33:26-37.

16. Kato, T., Tanabe, S., Nishimura, M., Ohtake, Y., Nishizawa, Y., Shimizu, T., Jikumaru, Y., Koga, J., Okada, K., and Yamane, H. 2009. Differential responses of rice to inoculation with wild-type and non-pathogenic mutants of Magnaporthe oryzae. Plant Mol. Biol. 70:617-625.

17. Kono, A., Sato, A., Nakano, M., Yamada, M., Mitani, N., and Ban, Y. 2012. Evaluating grapevine cultivars for resistance to anthracnose based on lesion number and length. Am. J. Enol. Vitic. 63(2):262-268.

18. Kumar, K. V. K., Reddy, M. S., Yellareddygari, S., Kloepper, J. W., Lawrence, K. S., Zhou, X. G., Sudini, H., and Miller, M. E. 2011. Evaluation and selection of elite plant growth-promoting Rhizobacteria for suppression of sheath blight of rice caused by Rhizoctonia solani in a detached leaf bioassay. Int. J. Appl. Biol. Pharmaceutical Technol. 2:488-495.

19. Liang, H., Maynard, C. A., Allen, R. D., and Powell, W. A. 2001. Increased Septoria musiva resistance in transgenic hybrid poplar leaves expressing a wheat oxalate oxidase gene. Plant Mol. Biol. 45:619-629.

20. Martinez-Bilbao, A., Ortiz-Barredo, A., Montesinos, E., and Murillo, J. 2009. Evaluation of a cider apple germplasm collection of local cultivars from Spain for resistance to fire blight (Erwinia amylovora) using a combination of inoculation assays on leaves and shoots. HortScience 44:1223 1227

21. Moralejo, E., Belbahri, L., Calmin, G., Garcia-Munoz, J., Lefort, F., and Descals, E. 2008. Strawberry tree blight in Spain, a new disease caused by various Phytophthora species. J. Phytopathol. 156:577-587.

22. Nyassé, S., Cilas, C., Herail, C., and Blaha, G. 1995. Leaf inoculation as an early screening test for cocoa (Theobroma cacao L.) resistance to Phytophthora black pod disease. Crop Prot. 14:657-663.

23. Pettitt, T. R., Wainwright, M. F., Wakeham, A. J., and White, J. G. 2011. A simple detached leaf assay provides rapid and inexpensive determination of pathogenicity of Pythium isolates to 'all year round' (AYR) chrysanthemum roots. Plant Pathol. 60:946-956.

24. Powell, W. A., Morley, P., King, M., and Maynard, C. A. 2007. Small stem chestnut blight resistance assay. J. Am. Chestnut Foundation 21:34-38.

25. Wally, O., Jayaraj, J., and Punja, Z. 2009. Comparative resistance to foliar fungal pathogens in transgenic carrot plants expressing genes encoding for chitinase, $\beta$-1, 3-glucanase and peroxidise. Eur. J. Plant Pathol. 123:331342.

26. Zhang, B., Oakes, A., Newhouse, A., Baier, K., Maynard, C., and Powell, W. 2013. A threshold level of oxalate oxidase transgene expression reduces Cryphonectria parasitica-induced necrosis in a transgenic American chestnut (Castanea dentata) leaf bioassay. Transgenic Res. 22(5):973-982. 